\title{
Can the microbiome influence host evolutionary trajectories?
}

\author{
Lucas P. Henry ${ }^{1,2^{*}}$, Marjolein Bruijning ${ }^{1}$, Simon K.G. Forsberg ${ }^{1,2}$, Julien F. Ayroles ${ }^{1,2^{*}}$ \\ 1. Dept. of Ecology and Evolutionary Biology, Princeton University \\ 2. Lewis Sigler Institute for Integrative Genomics, Princeton University \\ *email contacts: LPH lhenry@princeton.edu ; JFA jayroles@princeton.edu
}

\begin{abstract}
The microbiome shapes many traits in hosts, but we still do not understand how it influences host evolution. To impact host evolution, the microbiome must be heritable and have phenotypic effects on the host. However, the complex inheritance and context-dependence of the microbiome challenges traditional models of organismal evolution. Here, we take a multifaceted approach to identify conditions in which the microbiome influences host evolutionary trajectories. We explore quantitative genetic models to highlight how microbial inheritance and phenotypic effects can modulate host evolutionary responses to selection. We synthesize the literature across diverse taxa to find common scenarios of microbiome driven host evolution. First, hosts may leverage locally adapted microbes, increasing survivorship in stressful environments. Second, microbial variation may increase host phenotypic variation, enabling exploration of novel fitness landscapes. We further illustrate these effects by performing a meta-analysis of artificial selection in Drosophila, finding that bacterial diversity also frequently responds to host selection. We conclude by outlining key avenues of research and experimental procedures to improve our understanding of the complex interplay between hosts and microbiomes. By synthesizing perspectives through multiple conceptual and analytical approaches, we show how microbiomes can influence the evolutionary trajectories of hosts.
\end{abstract}

\section{Introduction}

The microbiome has emerged as a key determinant of many aspects of organismal biology, capable of shaping developmental, physiological, and reproductive phenotypes ${ }^{1-5}$. Yet, the contribution of the microbiome to host adaptation remains an evolutionary puzzle ${ }^{6-9}$. Microbiomes are traditionally viewed as non-genetic, environmental factors that influence host phenotypes. However, unlike abiotic environmental conditions, the effects of microbial variation have a genetic basis and can evolve ${ }^{10}$, but are not inherited in the same way as host genes ${ }^{6,7,9}$. Frequently, microbiomes have substantial phenotypic effects on their hosts, but these effects strongly depend on the ecological context $t^{2,8,11}$. Despite their clear importance, the complex effects of microbial inheritance and genetics on host phenotypes remain underappreciated, limiting our ability to understand host-microbiome evolution.

In this perspective piece, we explore how the microbiome influences host evolutionary trajectories. To assess the importance of the microbiome on host phenotypes and inheritance, we integrate the microbiome into quantitative genetic models to make predictions about the microbial impact on host evolutionary trajectories. We review techniques to measure host-microbiome evolution, highlighting current technical and theoretical limitations. Next, we detail two common scenarios found in the literature where the microbiome influences host evolution across a diverse range of host organisms. First, hosts may leverage locally adapted microbes. Second, microbial variation may increase host phenotypic variation, enabling exploration of novel fitness landscapes. Then, to better understand how microbiomes may influence host evolution, we perform a meta-analysis of experimental evolution in Drosophila to demonstrate that microbial diversity frequently responds to host adaptation. We conclude by suggesting key avenues of research and outline experimental approaches to improve our understanding of how and when the microbiome may influence host evolution. Through this perspective piece, we show how understanding host-microbial variation can provide fundamental insights into ecological and evolutionary trajectories.

\section{Extending the Host Genetic Repertoire}

Dawkins' Extended Phenotype recognized how organisms modify surrounding environments and the ecological community ${ }^{12}$. Through environmental modification, an organism's phenotypic effects are extended beyond its own genome, suggesting evolution is influenced through interacting ecological communities. This theory, developed for free-living ecosystems, also applies to host-microbiome interactions ${ }^{13,14}$. The microbiome, with its consortium of genomes, extends the genetic repertoire of the host to form what some are now calling the Extended Genotype because the host integrates the extended effects of the microbiome into its phenotype $e^{11,15-23}$ (Fig. 1). The evolutionary impact of the microbiome will depend on how host and microbial genetic variation are inherited and interact, shaping host phenotypes across generations.

Integrating microbial genetic variation into host evolutionary processes builds on hologenome theory. The hologenome is defined as an evolutionary unit combining the eukaryotic host and all associated microbes ${ }^{16,24,25}$. Under this concept, evolution operates on this single unit because eukaryotic hosts are never isolated from microbes in the natural world ${ }^{16,23}$. Thus, the evolutionary fate of both hosts and microbes is intertwined. The intertwined fate of a single hostmicrobiome evolutionary unit is the focus of much criticism of hologenome. Because of complicated vertical and environmental transmission routes of the microbiome, the host and microbiome rarely operate as one selective unit ${ }^{6,7,9}$. Moreover, the differences in evolutionary and ecological time scales between host and microbiome also challenge the utility of hologenome theory ${ }^{8}$. Advances in 
hologenome theory clarify the role of microbial variation in shaping host evolution: variation in the microbiome is associated with variation in host fitness, and hosts and microbiome evolve in response to selective pressures ${ }^{14,23,25,26}$. In turn, selection may operate on the microbiome, host, and their interaction in different ways ${ }^{25}$, but a phenotypic response is necessary to impact the host evolutionary trajectory 9 .

To formalize these verbal arguments, we propose quantitative genetic models that incorporate the contribution of the microbiome to host phenotype, and subsequent response to selection. Furthermore, we explore how fidelity of microbiome inheritance influences the response to selection. Together, this allows us to make predictions about how the microbiome influences host evolution (Box 1). Our simulations show that the microbiome can modulate the host evolutionary response, but this will depend on both the microbial contribution to host phenotypic variation and complexities of microbial inheritance.

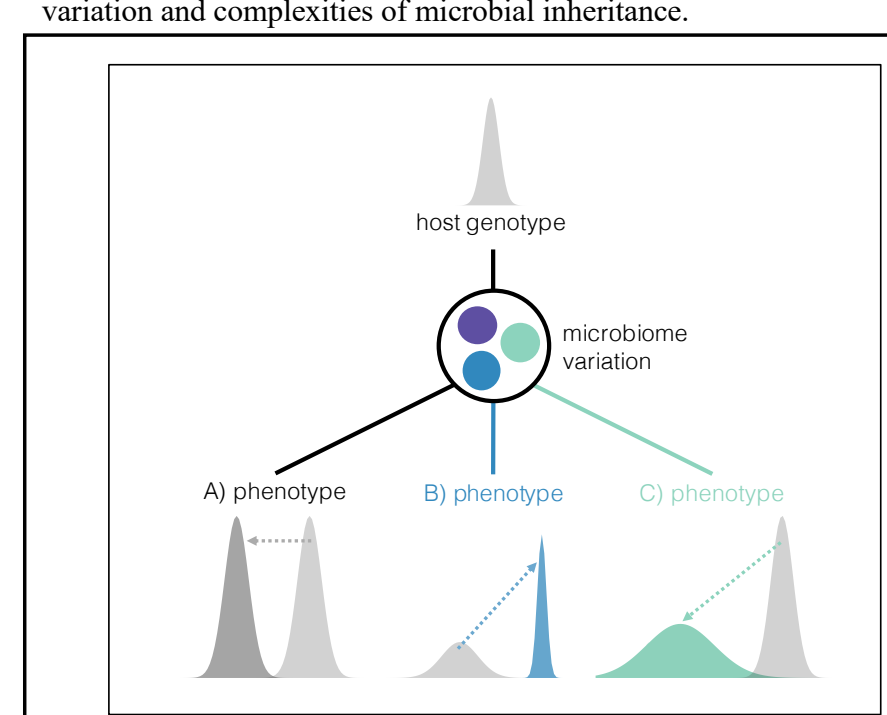

FIGURE 1: Conceptualization of the microbiome influence on host phenotype. The microbiome encodes many more genes than the host genome alone. Interactions with variation in the microbiome may alter the host genotype-phenotype map, shaping host phenotypic variation. A) First, we conceptualize the phenotypic variation encoded by the host genome alone in light grey. The presence of a microbiome might shift the mean of host phenotypes, visualized as the by the arrow to the darker grey distribution. In this scenario, the host is thus largely unaffected by microbial variation, but only by the presence of a microbiome. Additionally, not all microbes (e.g. in purple) will not influence host phenotypes. B) The microbiome may shift both the variance and the mean of host phenotypes. The blue distribution is suggestive of when host leverage locally adapted microbiomes to specialized phenotypes. C) Alternatively, the microbiome may also expand phenotypic variation, conceptualized in green. Expanding host phenotypic variation through the microbiome may allow hosts to explore novel fitness landscapes. These are conceptualized phenotypic distributions, and more experimental work is necessary to confirm how the microbiome affects host phenotypic distributions.

\section{A Complex Inheritance}

For the microbiome to influence host evolution, it must have host phenotypic effects and be inherited. From a quantitative genetics perspective, microbiome heritability is the resemblance of microbiomes between parents and offspring. The microbiome can be shared via strict vertical transmission through embryos, but many microbes are also transmitted through quasi-vertical and environmental modes, like vaginal birth in mammals, regurgitation in birds, environmental inoculation in insects, or coprophagy in many taxa $a^{27,28}$. Additionally, host genetics can structure microbial variation, just like other complex traits $^{29}$. Host genetic variation may lead to the preferential association of specific environmentally-acquired microbes ${ }^{30}$, leading to high parentoffspring similarity. Indeed, in hosts dominated by environmentally acquired microbes, the contribution of host genetic variation to the relative abundance of particular microbes is as high as $42 \%$ in humans ${ }^{31,32}, 39 \%$ in Drosophila ${ }^{33}$, and $25 \%$ in maize ${ }^{34}$. Interestingly, these and other studies show that not all components of the microbiome are heritable with only a portion of the microbiome faithfully transmitted, with estimates ranging from $8-56 \%$ of microbes $^{32,34-36}$.

The inheritance of the microbiome is complex and still poorly understood for several reasons. Some microbes are transmitted exclusively between parent and offspring, like typical host genetic inheritance, while others are environmentally acquired ${ }^{8,37}$. Environmental factors, like diet or climate, also substantially influence the reservoir of possible microbial partners, leading to changes in the microbiome independent of any host evolution ${ }^{38-40}$. Host phenotypes also may be more strongly shaped by distinct microbial variation early in life, but because microbial dynamics operate at shorter timescales than host generations, those relevant microbes may not be faithfully transmitted across host generations ${ }^{8,41,42}$. Such complexities muddle the inheritance of the microbiome, challenging how frequently the microbiome could influence host evolution ${ }^{6-9,25}$. Our simulations show how variation in microbial inheritance modulates the microbial contribution to host evolution (Box 1).

Microbes with beneficial phenotypic effects should be faithfully inherited. However, the drivers of this relationship between inheritance and phenotypic effects is not always clear. For example, in a UK twin study investigating the influence of host genetics on the microbiome, Methanobrevibacter species were identified to have the highest heritability and strong association with low body-mass index ${ }^{31,32}$. Similarly, though another study in humans found little influence of host genetics on microbiome composition, microbial variation still explained $22-36 \%$ of metabolic traits $^{39}$. Microbial variation explained $33 \%$ of weight gain in pigs $^{35}$ and $13 \%$ of methane emissions in cows ${ }^{36}$ but also occurred largely independently of host genetic control of the microbiome. In other words, we still do not know whether the most heritable microbes explain the most significant variation in host traits. However, despite the complicated inheritance of the microbiome, these studies suggest that for a range of host traits, the microbiome contributes almost as much to phenotypic variation as host genetics. Our simulations also suggest that when the microbiome shapes host phenotypic variation and is faithfully inherited, the microbiome can contribute substantially to the host selection response (Box 1), but there is currently little empirical data to validate these conclusions.

\section{Measuring the Microbiome Response To Selection}

With recent advances in sequencing technologies, microbial variation can be quantified at many different scales, from strains to whole community composition to complete metagenomes $\left(\mathrm{see}^{43}\right.$ for a recent review). A major challenge is to identify which scale of microbial variation (i.e. strain, community, metagenome) influences host phenotypes ${ }^{8,43,44}$. 


\section{BOX 1: QUANTITATIVE GENETICS OF HOST-MICROBIOME INTERACTIONS}

Quantitative genetic models traditionally decompose host phenotypic variance into genetic $\left(\mathrm{V}_{\mathrm{G}}\right)$ and environmental $\left(\mathrm{V}_{\mathrm{E}}\right)$ components. However, this simple model generally does not consider the contribution of the microbiome to host phenotypic variation. Extending this quantitative genetic framework to include the microbiome, we use simulations to explore the microbial contribution to host response to selection (see Supp. Methods for more detail).

Ignoring the contribution of epistasis and dominance effects and assuming no covariances between host genetic, microbial, and environmental effects, the total phenotypic variance can be modeled as:

$$
V_{P}=V_{G-H O S T}+V_{G-M I C R O}+V_{E} \quad \text { Eq. } 1
$$

Where $\mathrm{V}_{\mathrm{G}-\mathrm{HOST}}$ is the genetic variance in the host contributing to phenotype, $\mathrm{V}_{\mathrm{G}-\mathrm{MICRO}}$ is genetic variance in the microbiome contributing to phenotype, and $\mathrm{V}_{\mathrm{E}}$ is the environmental variance. $\mathrm{V}_{\mathrm{G}-\mathrm{MICRO}}$ is frequently quantified as relative abundance of specific microbes. However, with this framework, $\mathrm{V}_{\mathrm{G}-\mathrm{MICRO}}$ can be extended to genetic variation in the microbiome. If we start by assuming all microbial genetic variance is transmitted from parent to offspring, host heritability can be calculated as:

$$
h_{\text {TOTAL }}^{2}=h_{\text {HOST }}^{2}+h_{M I C R O}^{2}=\frac{V_{G-H O S T}+V_{G-M I C R O}}{V_{P}} \quad \text { Eq. } 2
$$

When the microbiome is transmitted across generations, so is the genetic variation the microbiome harbors. Increasing the microbial contribution to phenotype ( $\left.\mathrm{V}_{\mathrm{G}-\mathrm{MICRO}}\right)$ increases total host heritability (Fig A).

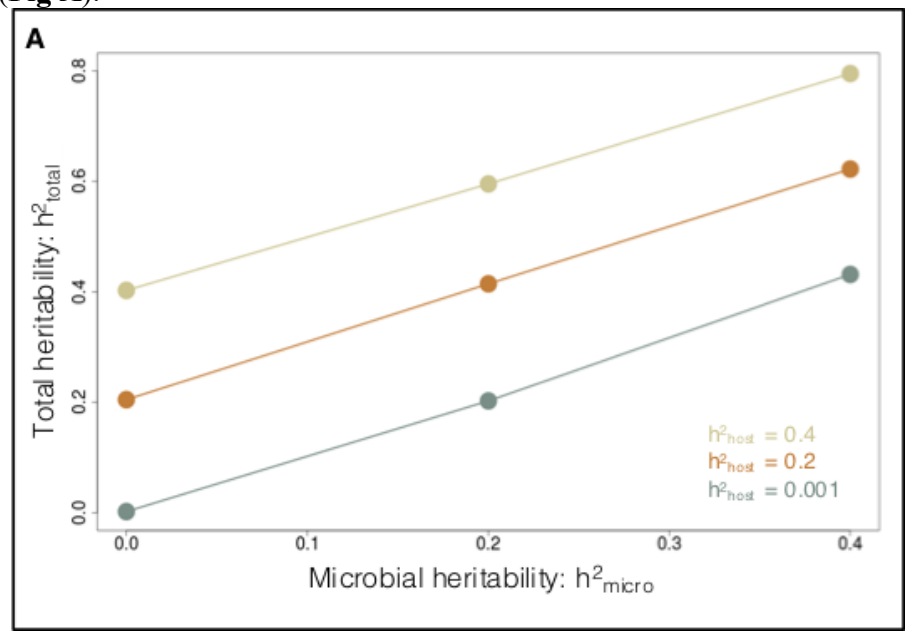

Given the complicated inheritance of the microbiome, we further explored how variation in transmission affects short-term host response to selection. The breeder's equation can be adjusted to reflect the variation in microbiome transmission:

$$
R=\left(h_{\text {HOST }}^{2}+T_{M I C R O}\right) \times S
$$

Eq. 3

Where $\mathrm{R}$ is the response to selection, $\mathrm{S}$ is selection coefficient, $\mathrm{h}^{2}{ }_{\text {HOST }}$ is the portion contributed by host genetic variation, and $\mathrm{T}_{\text {MICRO }}$ is a function modulating the contribution of the microbiome:

$$
T_{M I C R O}=f\left(\frac{h_{M I C R O}^{2}}{e}\right) \quad \text { Eq. } 4
$$

$\mathrm{T}_{\text {MICRO Scales }} \mathrm{h}^{2}$ MICRO, the microbial contribution to host heritability, by $e$ microbial transmission noise. In our simulations, we varied transmission noise across two conditions: high and negligible $\mathrm{h}^{2}{ }_{\mathrm{HOST}}$ (high $=0.4$, negligible $=0.0001$ ), while keeping $\mathrm{h}^{2}{ }_{\text {MICRO }}$ high (0.4).

Not surprisingly, the contribution of $\mathrm{h}^{2}$ MICRO to total heritability decreases as transmission noise increases. The microbiome can modulate the host response to selection, visualized in $\mathbf{B}$ and $\mathbf{C}$. For traits with high host genetic contribution $\left(\mathrm{h}^{2}{ }_{\text {HOST }}=0.4\right)$, the microbiome, if faithfully transmitted, contributes to the response to selection (Fig. B). However, as transmission noise increases, the microbial contribution decreases and modulates the response to selection. Second, for traits with negligible $h^{2}{ }_{\text {HOST, the microbiome }}$ alone has the potential to contribute significantly to selection response. The contribution will depend on transmission noise (Fig. C). Especially when $\mathrm{h}^{2}$ новт is low, the host response to selection will depend on how faithfully the microbiome is transmitted across host generations.
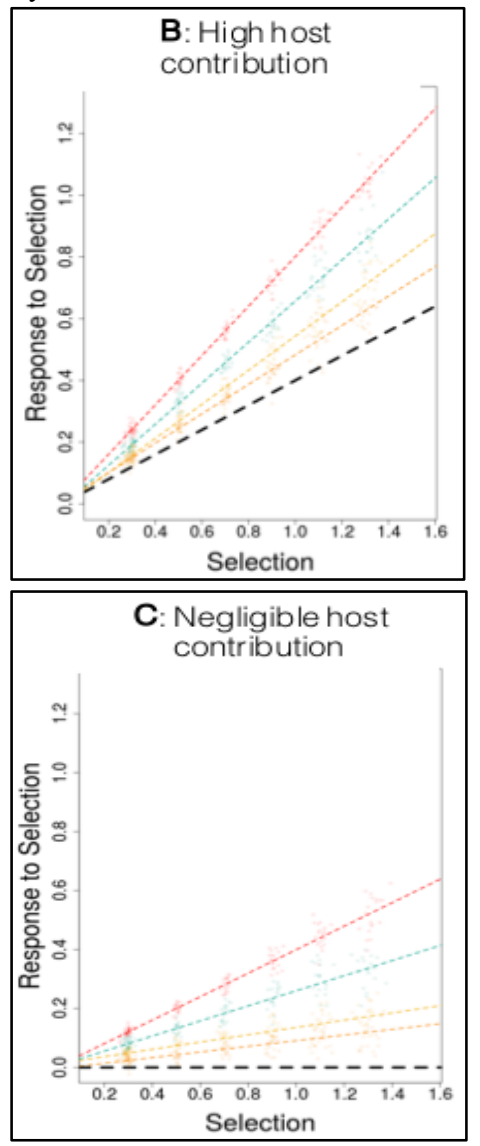

Our simulations highlight the importance of incorporating the microbiome into host evolutionary responses. To contribute, the microbiome must have phenotypic effects and be faithfully transmitted. Although there is a growing interest in quantifying the heritability of the microbiome, there is currently little empirical data available to estimate the variation in parameters used in these simulations. Future work is necessary to better understand the complex relationship between host genetic variation, microbial variation, and heritability. 
The majority of host-microbiome interactions are characterized through marker gene studies (i.e. 16S rRNA for bacteria, ITS for fungi). Marker genes can classify microbial communities at broad taxonomic levels, are relatively inexpensive to sequence, and have established bioinformatic and analytical pipelines ${ }^{43}$. This approach demonstrates that microbial communities respond to many different kinds of selective pressures, like drought ${ }^{45,46}$, antibiotics ${ }^{47,48}$, different $\operatorname{diets}^{49}$, or warming environments ${ }^{50}$. Some studies show that microbial community diversity decreases in response to stressful environments ${ }^{46-}$ 48 , while others show only shifts in community composition ${ }^{45,49,50}$. Marker gene studies are well-suited for taxonomically defining communities (though $\mathrm{se}^{51}$ ), but changes in microbial community composition do not always correlate to changes in host phenotype. For example, as measured by 16S rRNA marker genes, the macroalgae Ulva is colonized by different bacteria in different environments, but metagenomic data shows the same core functional genes encoded by different bacterial taxa ${ }^{52}$. Similar patterns are observed in human microbiomes $^{53}$ and the tree phyllosphere ${ }^{54,55}$. If the microbial genetic repertoire or host phenotypes do not respond to corresponding changes in the microbial communities, then the microbial variation likely has little adaptive value for hosts. However, this conclusion may be strongly impacted by how microbial variation is characterized. Therefore, techniques beyond marker gene classification are needed to determine if and how microbial variation influences the host response to selection.

Strain-level analyses of microbial variation (i.e. polymorphisms and other genetic variants beyond marker genes) may provide more functional insight into the microbiome response to selection. For example, strain-level variation in honey bee microbes influences the response to pathogens or different diets for the hosts ${ }^{56}$. Strain-level analyses also provide insights into the stability of the microbiome across the lifetime of the host $\mathrm{t}^{57-59}$ as well transmission dynamics $^{60,61}$. Metagenomes, which fully characterize the extended genotype, will provide crucial insights into functional variation of the microbiome ${ }^{43,56,62,63}$. For example, metagenomics demonstrated how bacterial metabolism varies across different niches within the same host $^{64}$. This approach however remains costly, computationally intensive, and the results can be difficult to interpret. The emerging field of metatranscriptomics aims to study gene expression in the complex microbial communities ${ }^{43,65,66}$. Linking the metagenome to the metatranscriptome will be particularly insightful to understand how microbial variation influence host phenotypic variation ${ }^{43,67}$. For example, by comparing metagenomes to metatranscriptomes in the human gut, it was discovered that only a few specialized bacteria express unique biosynthesis pathways that may reflect the microbiome response to changing diets or other environmental perturbations in hosts $^{67,68}$. Experimental approaches that compare how microbial genetic variation alters host gene expression (interspecies eQTLs ${ }^{69}$ ), and vice versa, provide a promising way forward to understand the links between host-microbiome response to selection at the whole system scale.

\section{Linking the Microbiome to Host Adaptive Responses}

Several analytical and theoretical gaps limit our current understanding of how the microbiome influences host evolution. First, while remarkable progress has been made in detailing microbial diversity, studies examining genetic variation in the microbiome (i.e. SNPs) beyond marker genes remain very limited ${ }^{43,59}$. The growing number of metagenomic studies will answer some questions, but more advanced bioinformatic tools are needed to connect strain-level microbial variation to host phenotypic effects. On the theoretical side, many aspects of microbial evolution--like demography, pangenomes, horizontal gene transfer, unique population structure--may poorly match the assumptions of more traditional population genetic models of freeliving organisms ${ }^{59,70-72}$. Can we, for example, apply indirect selection ${ }^{13}$ or multilevel selection models (i.e. Price equation) $)^{44}$ to ask how independent or synergistic are host and microbiome evolution? One novel approach to understand the signatures of microbial variation shaping host evolution is interspecies linkage disequilibrium ${ }^{73}$. Interspecies linkage disequilibrium may occur when beneficial combinations of host and microbiome alleles jointly increase host

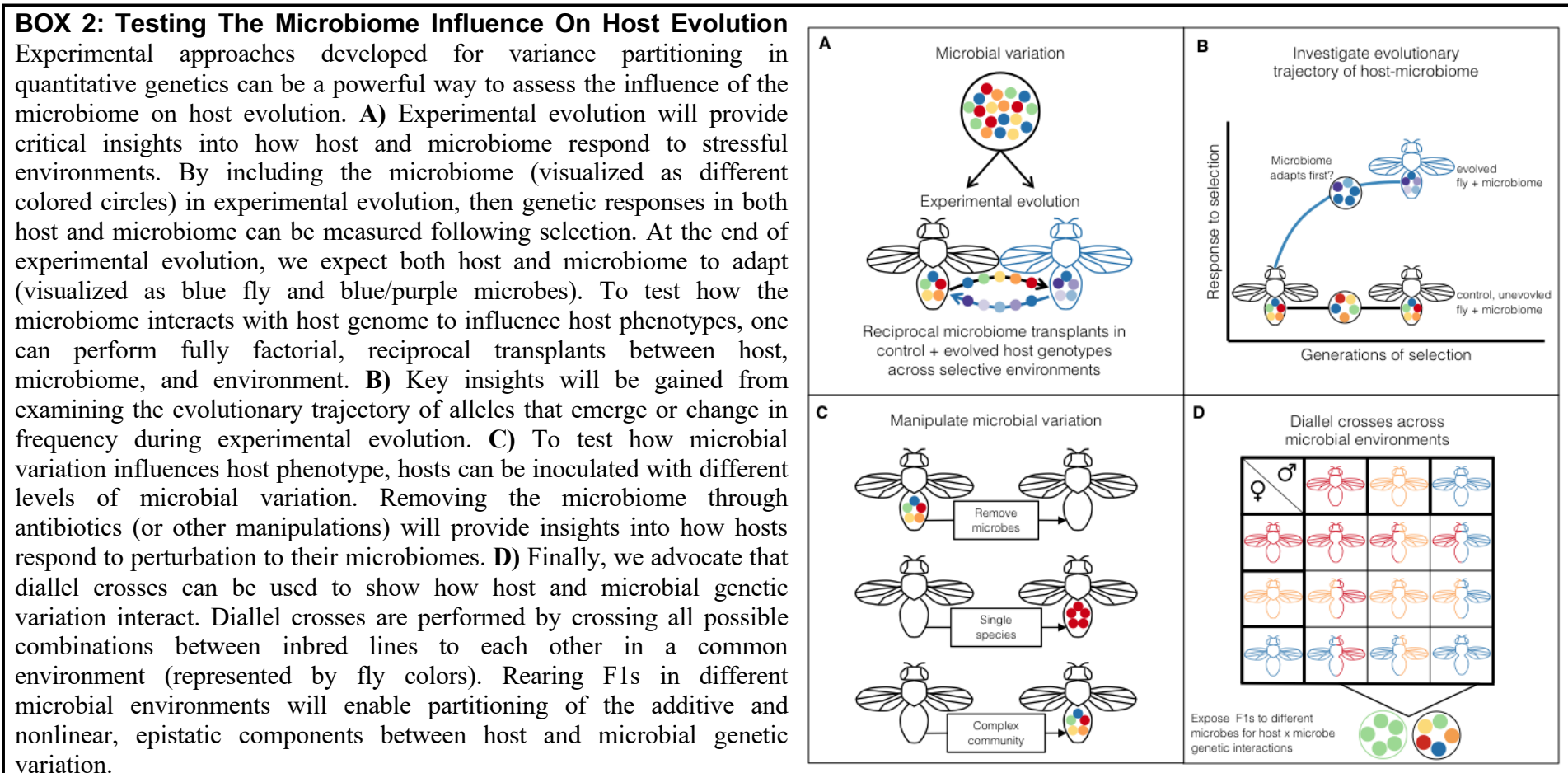


fitness. If so, selection may operate on the linkage, resulting in nonrandom allelic assortment of beneficial microbes and host genetic variation. The challenge is to identify which and how frequently variation in the microbiome increases host fitness, and whether this increases the probability of transmission across host generations.

Developing meaningful null models to describe hostmicrobiome evolution is a nontrivial challenge. First, we lack empirical data to calibrate a null model, like when the microbiome does not influence host phenotypes. Second, the null model should consider the balance in evolutionary interests between host and microbiome. Hosts and microbiomes will rarely have perfectly aligned evolutionary interests, suggesting a balance between cooperation and conflict ${ }^{6,8,41}$. For example, intergenomic conflict is likely to have important consequences for host-microbe coevolution because environmentally acquired microbes face vastly different evolutionary pressures inside and outside of hosts. Intergenomic conflict may maintain variation in microbial associations, but how often this influences host-microbiome evolution is not well understood ${ }^{74}$. Ultimately, the null hypothesis should consider the balance between cooperation, conflict, and indifference between the host and microbiome during adaptation.

Ultimately, rigorous sampling across time and space will be key to illuminating drivers of host-microbiome evolution. Within the last 10 years, researchers have started to identify how the microbiome influences host evolutionary processes in diverse taxa and environments. We synthesized the literature and find evidence suggestive of two common scenarios in how the microbiome may shape host evolution: 1) hosts leverage locally adapted microbes, and 2) the microbiome increases host intraspecific phenotypic variation. These scenarios are not mutually exclusive, but as we explain below, suggest different evolutionary trajectories for hosts.

\section{Hosts Leverage Locally Adapted Microbes}

In stressful environments, hosts may leverage locally adapted microbes. Microbes with larger effective population sizes, rapid generation time, and pangenomes may evolve novel functions faster than their hosts ${ }^{75-78}$. If hosts can capitalize on locally adapted microbes, then hosts can increase survivorship and rapidly adapt to novel environments.

There are a number of remarkable studies that illustrate the substantial impact of locally adapted microbes on hosts, suggesting that microbes may underlie host adaptation to populations in stressful environments. For example, bean bugs can gain pesticide resistance through acquiring a pesticide degrading soil bacterium, Burkholderia ${ }^{79}$ 81. Many other hosts utilize their microbiome to detoxify harmful chemicals. The woodrat microbiome degrades terpenes, enabling the woodrat to live in a specialized dietary niche ${ }^{82-86}$. Bark beetles ${ }^{87}$, pine weevils $^{88}$, and coffee berry borers ${ }^{89}$ also use their microbiomes to detoxify plant secondary compounds in specialized niches. The microbiome can also facilitate survival in other kinds of stressful environments. Plants on geothermal soils are associated with the thermotolerant endophyte Curvularia ${ }^{90}$. Thermotolerant Curvularia can increase survival up to $40^{\circ} \mathrm{C}$ in non-adapted tomatoes, while Curvularia isolated from non-geothermal soils did not ${ }^{91}$. Additionally, salt tolerant fungi can also confer salt tolerance to non-adapted plants ${ }^{91}$. Coral modify their microbiomes in response to temperature stressors and pathogens, facilitating survival in rapidly changing oceans ${ }^{92-94}$. These examples show that hosts can utilize specific microbial genotypes or communities with large phenotypic effects to specialize and persist in novel niches.

Relying on locally-adapted microbes may facilitate evolution in the short term--but what are the evolutionary consequences of host reliance on locally adaptive, environmentally-acquired microbes? The evolutionary benefit may allow hosts to rapidly cross the fitness landscape. Then, hosts should evolve to maintain the locally adapted microbes and their modification to the environment, much like genetic accommodation or niche construction ${ }^{95}$. However, relying on environmentally acquired microbes increases stochasticity in the microbiome, exposing offspring to pathogens and non-adaptive microbes. If specific microbes are beneficial, hosts should evolve mechanisms to ensure faithful microbial transmission, like traditional symbioses ${ }^{96}$. While still contentious if most microbiomes behave like traditional symbioses, ultimately, strict vertical transmission and extreme reliance on specialized microbes is likely an evolutionary dead end, constraining hosts and microbes to the ecological conditions that generated the symbiosis ${ }^{97}$. Overall, the challenge remains in determining how microbial genetic variation is linked with and influences host genetic change during adaptation.

\section{Microbial Variation Shapes Host Intraspecific Phenotypic Variation}

In the case of locally-adaptive microbiomes, specific microbes enable host survival by optimizing phenotype to match specific stressors, shrinking host phenotypic variation (Fig. 1). However, in other cases, stochastic variation and priority effects during microbial community assembly may create microbial variation between hosts $^{8,42,98}$. Such an increase in microbial variation may increase phenotypic variation in host population, enabling more individuals to explore broader phenotypic spaces ${ }^{99,100}$ (Fig. 1). Microbial variation would then enable the exploration of new fitness landscapes where hosts may more rapidly find novel solutions to stressful environments.

Microbial variation increases host phenotypic variation in many organisms. For example, in Drosophila, different microbial communities increase the variance in larval development time, pupal weight, and adult weight compared to sterile flies ${ }^{101,102}$. In Daphnia, different bacteria increase variance in body size and hatching success compared to sterile treatments ${ }^{103}$. Microbiomes evolved for rapid flowering time in Arabidopsis increased variance in biomass compared to microbiomes evolved for slow flowering time ${ }^{104}$. In zebrafish, different microbes are associated with varying immune responses ${ }^{105}$. In all these cases, hosts are permissive to colonization by many microbes, and in turn, phenotypes respond to microbial variation. A major question for host-microbiome evolution is why some host phenotypes are responsive to microbial variation while others maintain more constant traits (i.e they are more canalized)?

Maintaining responsive phenotypes to microbial variation may allow hosts to better match phenotypes to current environmental stressors ${ }^{17,18}$. For hosts where offspring might occupy different environments than parents, microbes may provide critical cues for local environments. For example, microbes evolved under drought led to early flowering in both Arabidopsis and Brassica ${ }^{104,106}$, suggesting that microbes signal local growing conditions and changes in life-history strategies. For Daphnia, microbes acquired from their local environment increased fecundity compared to those acquired via maternal transmission before diapause ${ }^{103}$. To best match phenotype to local environment, hosts may use microbial variation to alter 
developmental timing. Development in many taxa, from insects ${ }^{107-113}$ to plants $^{114-116}$ to crustaceans ${ }^{117,118}$, changes in response to microbial variation. Developmental plasticity, through microbial variation, may expose novel phenotypic variation ${ }^{119}$, and this may in turn generate phenotypes that allow rapid acclimation to variable environments. Hosts may evolve to maintain variable microbial associations that best match phenotypes to current environments.

Phenotypes that are responsive to diverse microbial associations may alternatively pose a risk to the host. Microbial variation may lead to mismatches between host and environment that reduce host fitness, like in the case of westernized human microbiomes leading to increased risk of obesity in immigrants in the United States $^{120}$. Ultimately, relying on environmentally acquired microbes depends on the microbes providing honest signals of local environmental conditions ${ }^{11,119,121}$. Identifying how hosts utilize environmentally acquired microbes to match phenotypes to environments is understudied, but essential to understanding the evolutionary benefits of the microbiome.

\section{Using Experimental Evolution To Characterize Microbial Influence}

Above, we identified common scenarios of how the microbiome may influence host evolutionary processes. To provide more mechanistic insight into host-microbiome evolutionary processes, experimental evolution can provide a powerful approach to understand how microbial change interacts with host evolution ${ }^{14,113,122}$. However, few studies have actually explicitly evaluated evolutionary responses in the microbiome. To illustrate how the microbiome responds to experimental evolution, we re-analyzed genomic data from 10 Evolve and Resequence $(\mathrm{E} \& \mathrm{R})^{123}$ experiments in D. melanogaster ${ }^{124-132}$ to characterize variation in the microbiome. We compared bacterial diversity between control and evolved populations to measure the microbial response to selection (see Supp. Methods for more detail).

We found that bacterial diversity frequently responded to experimental evolution (Fig. 2A). Evolved populations often exhibited reduced bacterial diversity (4/10 studies), though in one case (accelerated development time), increased bacterial diversity. Because each E\&R experiment varied in length of selection (from 5-605 Drosophila generations), we also tested if change in microbial diversity was correlated with host generations of selection. Change in microbial diversity was only weakly correlated with host generations of selection (Fig. 2B, $r=0.26, \mathrm{p}=0.02$ ). The specific nature of the selective pressure is more important in driving changes in the evolving microbiome. For example, the evolved microbiome in starvation resistance exhibited the greatest change in bacterial diversity (Fig. 2B), and the Drosophila microbiome is tightly linked to the regulation of metabolic networks ${ }^{133}$. For other traits, like egg size, the microbiome did not respond to experimental evolution. This meta-analysis suggests that the effect of selection on microbiome is likely trait specific.

Our meta-analysis suggests that the microbiome evolves with the host during experimental evolution. However, like other studies, we are only observing the endpoint of the host-microbiome evolutionary trajectory. Ultimately, understanding how microbiome alters the evolutionary trajectory in hosts is the critical missing link ${ }^{122,134-141}$. Monitoring the temporal dynamics during experimental evolution can

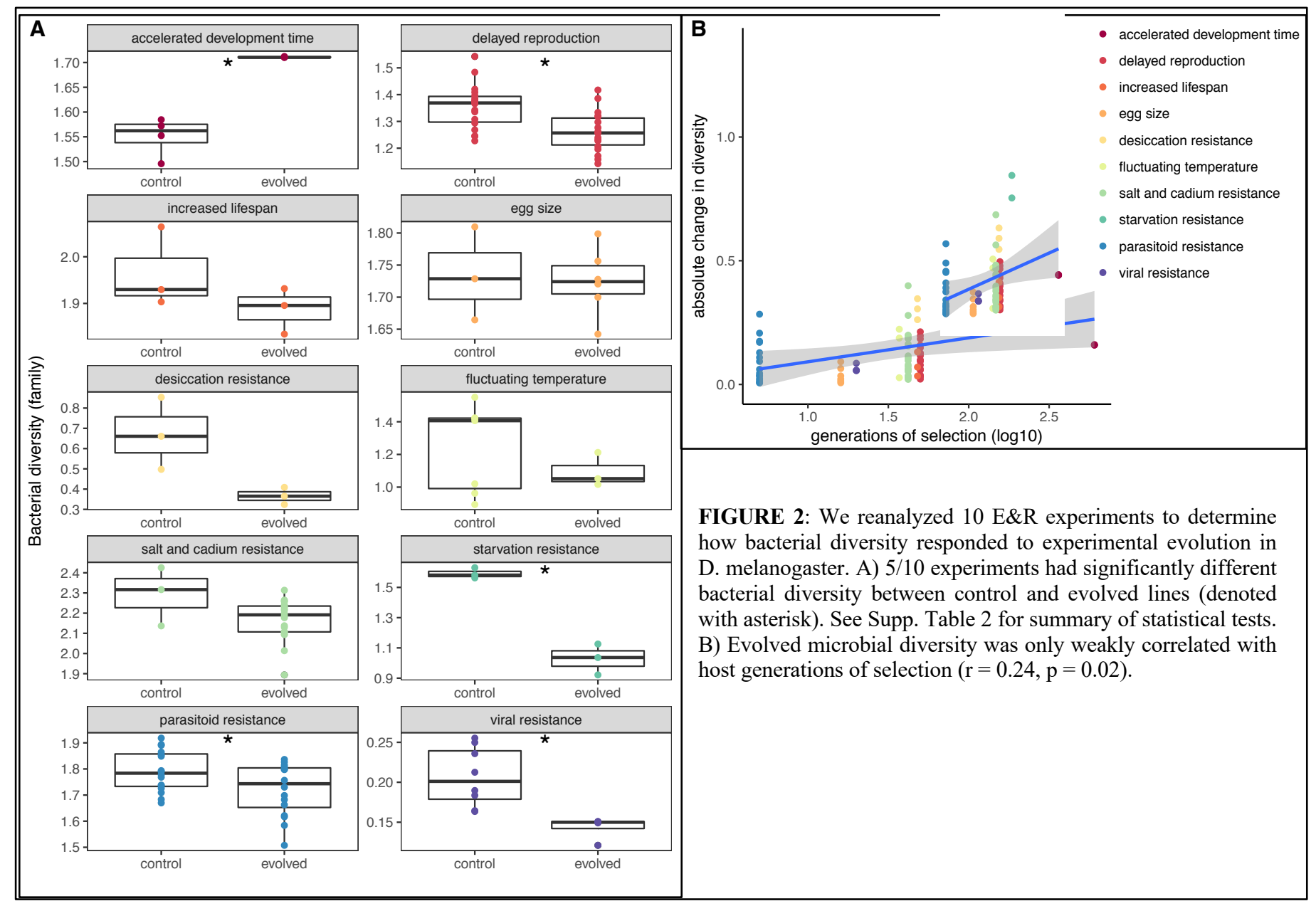


provide the missing link--specifically, does the microbiome adapt faster than the host? And how frequently does the host utilize this rapid microbial evolution? A recent study, where the temporal evolutionary dynamics were monitored, suggests that Lactobacillus bacteria in Drosophila evolve rapidly to nutrient poor diets, and Drosophila can leverage rapid microbial adaptation independent of their own evolution ${ }^{113}$. More experiments are needed that combine genotyping and phenotyping host-microbiome interactions to understand the temporal evolutionary dynamics. We outline how experimental evolution, combined with other tools commonly used in quantitative genetics, can provide deep insights into how the microbiome influences the host evolutionary trajectory (Box 2).

\section{A Practical Outlook}

Based on the examples discussed above, we show that the microbiome can influence host phenotypes and their evolutionary trajectory across taxa and diverse environments. Natural variation in the microbiome may also provide new tools to combat a range of challenges with practical applications. Indeed, there are several promising avenues of research leveraging natural microbial variation in fields ranging from conservation biology to agriculture. For example, variants of Pseudomonas bacteria isolated from caves help protect vulnerable bats from the devastating fungal infections of white-nose syndrome $^{142,143}$. A similar strategy is also in development to protect amphibians from chytrid pathogens ${ }^{144}$. From a public health perspective, manipulating the microbiome in disease vectors may reduce vector competence ${ }^{145}$. The success of cancer management can be influenced by the presence of particular gut microbes in humans, and finding novel probiotics to improve the efficacy of chemotherapy is under development ${ }^{146}$. Isolating host-associated microbiomes from organisms in extreme environments, like geothermal soils ${ }^{90,91}$, will serve as reservoir of adaptive microbes for agriculture in changing environments ${ }^{14,147}$. Natural variation in the microbiome represents a largely untapped resource with many novel solutions to address applied challenges.

\section{Conclusions}

Here, we have explored how the microbiome influences host evolution. Through synthesizing the literature, modeling, and metaanalyses, we identify conditions when the microbiome has the greatest potential to influence host evolution. Nevertheless, several key evolutionary questions remain to be addressed (Box 3): How do ecological interactions between microbes shape host phenotypes? What is the genetic basis of host responsiveness to microbial variation? How does the microbiome change host adaptive response? And, do the results of lab studies apply to microbiomes in the wild? Answering these questions will require a diversity of approaches using tools from quantitative genetics, community ecology, and genomics. We advocate for integrative experiments that leverage experimental evolution and natural variation to understand how the microbiome shapes host evolution (Box 2). More work, particularly in natural systems, is especially critical to find generalities of host-microbiome evolution.

In conclusion, the complex interplay between host and microbial genetic variation is surprisingly understudied. We find that the microbiome frequently shapes host phenotypic variation across diverse taxa and environments. In doing so, the microbiome may enable hosts to more rapidly explore the fitness landscape than the host could on its own. Studying the interplay between host and microbial genetic variation is complicated, but continuing advances in sequencing technology will facilitate the necessary characterization. Incorporating microbial variation will provide fundamental insights into how phenotypic variation is generated, and subsequently, how selection operates across ecological and evolutionary scales.

\section{BOX 3: Key questions and research priorities}

How does the microbiome change the host's adaptive response to stressful environments? Our E\&R meta-analysis suggests the microbiome also responds to selection. When the microbiome responds to selection, then does the microbiome reach a new adaptive peak before the host? Does the microbiome reinforce or dilute the selective forces acting on the host? Sequencing and microbiome transplantation along the course of experimental evolution will provide key insights into the role of microbiome in host adaptation. Equally important is investigating systems where microbes do not impact host adaptation $^{6,44,148}$.

How does microbial community assembly interact with host development to shape host phenotypes? How do microbe-microbe interactions influence host phenotype? How does community assembly interact with host developmental to shape host phenotype? Integrative work where permutations of bacterial communities colonize controlled host genotypes in Arabidopsis ${ }^{149,150}$ and Drosophila ${ }^{107,151,152}$ are important first steps; the challenge remains in applying this approach across different stressors as well as to non-model systems in the laboratory and field.

What is the genetic basis underlying host responses to microbial variation? Are there microbes (or genes) with disproportionately large effects on host phenotype? Do few host genes enable specificity or promiscuity in microbial associations? What host genes integrate and transform microbial variation into phenotypic variation? To understand how host and microbial genomes interact, we will need to combine common marker gene sequencing approaches with new approaches in characterizing microbial genetic variation at the strain level ${ }^{153-155}$. Computational approaches that ask how variation in the microbiome interacts with host genetic variation, like interspecies linkage disequilibrium $^{156}$-and interspecies eQTLs ${ }^{69}$, will illustrate mechanistic processes underlying microbiome-driven host adaptation.

What ecological and evolutionary forces structure microbiomes in the wild? What abiotic and biotic pressures influence microbial variation? How faithfully are microbiomes transmitted across generations and/or environments? How frequently do microbiomes influence host fitness in the wild? To answer these questions, researchers should following best practices to sample the microbiome in both hosts and the environment ${ }^{43,157,158}$. Identifying how the microbiome is transmitted and maintained in the wild will be crucial to understanding how the environmentally acquired microbiome shapes evolutionary processes.

\section{Acknowledgements}

We would like to thank Sarah Kocher, Amanda Lea, Jess Metcalf, Lindy McBride, and Luisa Pallares for helpful feedback.

\section{Code Availability}

Code for simulations and E\&R microbiome analyses can be found at https://github.com/lphenry/extgeno. 
bioRxiv preprint doi: https://doi.org/10.1101/700237; this version posted July 14, 2019. The copyright holder for this preprint (which was not certified by peer review) is the author/funder. All rights reserved. No reuse allowed without permission.

Henry al., 10072019 - preprint copy - BioRxiv

\section{References}

1. Blaser, M. J. \& Falkow, S. What are the consequences of the disappearing human microbiota? Nat. Rev. Microbiol. 7, 887-894 (2009).

2. Friesen, M. L. et al. Microbially Mediated Plant Functional Traits. Annu. Rev. Ecol. Evol. Syst. 42, 23-46 (2011).

3. McFall-Ngai, M. et al. Animals in a bacterial world, a new imperative for the life sciences. Proceedings of the National Academy of Sciences 110, 3229-3236 (2013).

4. Douglas, A. E. Symbiosis as a general principle in eukaryotic evolution. Cold Spring Harb. Perspect. Biol. 6, (2014).

5. Stappenbeck, T. S. \& Virgin, H. W. Accounting for reciprocal hostmicrobiome interactions in experimental science. Nature 534, 191199 (2016).

6. Moran, N. A. \& Sloan, D. B. The Hologenome Concept: Helpful or Hollow? PLoS Biol. 13, e1002311 (2015).

7. Douglas, A. E. \& Werren, J. H. Holes in the Hologenome: Why HostMicrobe Symbioses Are Not Holobionts. MBio 7, e02099 (2016).

8. Koskella, B., Hall, L. J. \& Metcalf, C. J. E. The microbiome beyond the horizon of ecological and evolutionary theory. Nat Ecol Evol 1, 1606-1615 (2017).

9. Morimoto, J. \& Baltrus, D. A. The Extended Genotype: To What Extent? A Comment on Carthey et al. Trends Ecol. Evol. (2019).

10. Scheuring, I. \& Yu, D. W. How to assemble a beneficial microbiome in three easy steps. Ecol. Lett. 15, 1300-1307 (2012).

11. McFall-Ngai, M. et al. Animals in a bacterial world, a new imperative for the life sciences. Proceedings of the National Academy of Sciences 110, 3229-3236 (2013).

12. Dawkins, R. The Extended Phenotype: The Long Reach of the Gene. (Oxford University Press, USA, 1982).

13. Whitham, T. G. et al. A framework for community and ecosystem genetics: from genes to ecosystems. Nat. Rev. Genet. 7, 510-523 (2006).

14. Mueller, U. G. \& Sachs, J. L. Engineering Microbiomes to Improve Plant and Animal Health. Trends Microbiol. 23, 606-617 (2015).

15. Zilber-Rosenberg, I. \& Rosenberg, E. Role of microorganisms in the evolution of animals and plants: the hologenome theory of evolution. FEMS Microbiol. Rev. 32, 723-735 (2008).

16. Bordenstein, S. R. \& Theis, K. R. Host Biology in Light of the Microbiome: Ten Principles of Holobionts and Hologenomes. PLOS Biol. 13, e1002226 (2015).

17. Alberdi, A., Aizpurua, O., Bohmann, K., Zepeda-Mendoza, M. L. \& Gilbert, M. T. P. Do Vertebrate Gut Metagenomes Confer Rapid Ecological Adaptation? Trends Ecol. Evol. 31, 689-699 (2016).

18. Shapira, M. Gut Microbiotas and Host Evolution: Scaling Up Symbiosis. Trends Ecol. Evol. 31, 539-549 (2016).

19. Carrier, T. J. \& Reitzel, A. M. The Hologenome Across Environments and the Implications of a Host-Associated Microbial Repertoire. Front. Microbiol. 8, 802 (2017).

20. Hurst, G. D. D. Extended genomes: symbiosis and evolution. Interface Focus 7, 20170001 (2017).

21. Sudakaran, S., Kost, C. \& Kaltenpoth, M. Symbiont Acquisition and Replacement as a Source of Ecological Innovation. Trends Microbiol. 25, 375-390 (2017).

22. Carthey, A. J. R., Gillings, M. R. \& Blumstein, D. T. The Extended Genotype: Microbially Mediated Olfactory Communication. Trends Ecol. Evol. 33, 885-894 (2018).

23. Rosenberg, E. \& Zilber-Rosenberg, I. The hologenome concept of evolution after 10 years. Microbiome 6, 78 (2018).

24. Rosenberg, E., Koren, O., Reshef, L., Efrony, R. \& ZilberRosenberg, I. The role of microorganisms in coral health, disease and evolution. Nat. Rev. Microbiol. 5, 355-362 (2007).
25. Theis, K. R. et al. Getting the Hologenome Concept Right: an EcoEvolutionary Framework for Hosts and Their Microbiomes. mSystems 1, (2016).

26. Carthey, A. J. R., Gillings, M. R. \& Blumstein, D. T. Microbial Genomes as Extension Packs for Macroorganismal Diversity: A Reply to Morimoto and Baltrus. Trends Ecol. Evol. (2019). doi:10.1016/j.tree.2019.01.001

27. Funkhouser, L. J. \& Bordenstein, S. R. Mom knows best: The universality of maternal microbial transmission. PLOS Biol. 11, e1001631 (2013).

28. Salem, H., Florez, L., Gerardo, N. \& Kaltenpoth, M. An out-of-body experience: the extracellular dimension for the transmission of mutualistic bacteria in insects. Proceedings of the Royal Society of London B: Biological Sciences 282, (2015).

29. Benson, A. K. The gut microbiome-an emerging complex trait. Nat. Genet. 48, 1301 (2016).

30. Beilsmith, K. et al. Genome-wide association studies on the phyllosphere microbiome: Embracing complexity in host--microbe interactions. Plant J. (2019).

31. Goodrich, J. K. et al. Human genetics shape the gut microbiome. Cell 159, 789-799 (2014).

32. Goodrich, J. K. et al. Genetic Determinants of the Gut Microbiome in UK Twins. Cell Host Microbe 19, 731-743 (2016).

33. Early, A. M., Shanmugarajah, N., Buchon, N. \& Clark, A. G. Drosophila Genotype Influences Commensal Bacterial Levels. PLOS One 12, e0170332 (2017).

34. Walters, W. A. et al. Large-scale replicated field study of maize rhizosphere identifies heritable microbes. Proc. Natl. Acad. Sci. U. S. A. 115, 7368-7373 (2018).

35. Camarinha-Silva, A. et al. Host Genome Influence on Gut Microbial Composition and Microbial Prediction of Complex Traits in Pigs. Genetics 206, 1637-1644 (2017).

36. Difford, G. F. et al. Host genetics and the rumen microbiome jointly associate with methane emissions in dairy cows. PLoS Genet. 14, e1007580 (2018).

37. Bright, M. \& Bulgheresi, S. A complex journey: transmission of microbial symbionts. Nat. Rev. Microbiol. 8, 218-230 (2010).

38. Vacher, C. et al. The Phyllosphere: Microbial Jungle at the PlantClimate Interface. Annu. Rev. Ecol. Evol. Syst. 47, 1-24 (2016).

39. Rothschild, D. et al. Environment dominates over host genetics in shaping human gut microbiota. Nature 555, 210-215 (2018).

40. Grieneisen, L. E. et al. Genes, geology and germs: gut microbiota across a primate hybrid zone are explained by site soil properties, not host species. Proceedings of the Royal Society B: Biological Sciences 286, 20190431 (2019).

41. McKenney, E. A., Koelle, K., Dunn, R. R. \& Yoder, A. D. The ecosystem services of animal microbiomes. Mol. Ecol. 27, 21642172 (2018).

42. Sprockett, D., Fukami, T. \& Relman, D. A. Role of priority effects in the early-life assembly of the gut microbiota. Nat. Rev. Gastroenterol. Hepatol. 15, 197-205 (2018).

43. Knight, R. et al. Best practices for analysing microbiomes. Nat. Rev. Microbiol. 16, 410-422 (2018).

44. Klassen, J. L. Defining microbiome function. Nat Microbiol 3, 864869 (2018).

45. Lau, J. A. \& Lennon, J. T. Rapid responses of soil microorganisms improve plant fitness in novel environments. Proc. Natl. Acad. Sci. U. S. A. 109, 14058-14062 (2012).

46. $\mathrm{Xu}, \mathrm{L}$. et al. Drought delays development of the sorghum root microbiome and enriches for monoderm bacteria. Proc. Natl. Acad. Sci. U. S. A. 115, E4284-E4293 (2018).

47. Cho, I. \& Blaser, M. J. The human microbiome: at the interface of health and disease. Nat. Rev. Genet. 13, 260-270 (2012). 
bioRxiv preprint doi: https://doi.org/10.1101/700237; this version posted July 14,2019 . The copyright holder for this preprint (which was not certified by peer review) is the author/funder. All rights reserved. No reuse allowed without permission.

Henry al., 10072019 - preprint copy - BioRxiv

48. Raymann, K., Bobay, L.-M. \& Moran, N. A. Antibiotics reduce genetic diversity of core species in the honeybee gut microbiome. Mol. Ecol. 27, 2057-2066 (2018).

49. David, L. A. et al. Diet rapidly and reproducibly alters the human gut microbiome. Nature 505, 559-563 (2014).

50. Ziegler, M., Seneca, F. O., Yum, L. K., Palumbi, S. R. \& Voolstra, C. R. Bacterial community dynamics are linked to patterns of coral heat tolerance. Nat. Commun. 8, 14213 (2017).

51. Pollock, J., Glendinning, L., Wisedchanwet, T. \& Watson, M. The Madness of Microbiome: Attempting To Find Consensus 'Best Practice' for 165 Microbiome Studies. Appl. Environ. Microbiol. 84, e02627-17 (2018).

52. Roth-Schulze, A. J. et al. Functional biogeography and host specificity of bacterial communities associated with the Marine Green Alga Ulva spp. Mol. Ecol. 27, 1952-1965 (2018).

53. Lozupone, C. A., Stombaugh, J. I., Gordon, J. I., Jansson, J. K. \& Knight, R. Diversity, stability and resilience of the human gut microbiota. Nature 489, 220-230 (2012).

54. Meaden, S., Metcalf, C. J. E. \& Koskella, B. The effects of host age and spatial location on bacterial community composition in the English Oak tree (Quercus robur). Environ. Microbiol. Rep. 8, 649$658(2016)$.

55. Lambais, M. R., Barrera, S. E., Santos, E. C., Crowley, D. E. \& Jumpponen, A. Phyllosphere Metaproteomes of Trees from the Brazilian Atlantic Forest Show High Levels of Functional Redundancy. Microb. Ecol. 73, 123-134 (2017).

56. Kwong, W. K. \& Moran, N. A. Gut microbial communities of social bees. Nat. Rev. Microbiol. 14, 374-384 (2016).

57. Franzosa, E. A. et al. Identifying personal microbiomes using metagenomic codes. Proc. Natl. Acad. Sci. U. S. A. 112, E2930-8 (2015).

58. Oh, J. et al. Temporal Stability of the Human Skin Microbiome. Cell 165, 854-866 (2016).

59. Garud, N. R., Good, B. H., Hallatschek, O. \& Pollard, K. S. Evolutionary dynamics of bacteria in the gut microbiome within and across hosts. PLoS Biol. 17, e3000102 (2019).

60. Asnicar, F. et al. Studying Vertical Microbiome Transmission from Mothers to Infants by Strain-Level Metagenomic Profiling. mSystems 2, (2017).

61. Yassour, M. et al. Strain-Level Analysis of Mother-to-Child Bacterial Transmission during the First Few Months of Life. Cell Host Microbe 24, 146-154.e4 (2018).

62. Fierer, N. Embracing the unknown: disentangling the complexities of the soil microbiome. Nat. Rev. Microbiol. 15, 579-590 (2017).

63. Gilbert, J. A. et al. Current understanding of the human microbiome. Nat. Med. 24, 392-400 (2018).

64. Abubucker, S. et al. Metabolic reconstruction for metagenomic data and its application to the human microbiome. PLoS Comput. Biol. 8 , e1002358 (2012).

65. Jorth, P. et al. Metatranscriptomics of the human oral microbiome during health and disease. MBio 5, e01012-14 (2014).

66. Bashiardes, S., Zilberman-Schapira, G. \& Elinav, E. Use of Metatranscriptomics in Microbiome Research. Bioinform. Biol. Insights 10, 19-25 (2016).

67. Franzosa, E. A. et al. Relating the metatranscriptome and metagenome of the human gut. Proc. Natl. Acad. Sci. U. S. A. 111, E2329-38 (2014).

68. Abu-Ali, G. S. et al. Metatranscriptome of human faecal microbial communities in a cohort of adult men. Nat Microbiol 3, 356-366 (2018).

69. Guo, Y. et al. Networks Underpinning Symbiosis Revealed Through Cross-Species eQTL Mapping. Genetics 206, 2175-2184 (2017).
70. Hanage, W. P. Not So Simple After All: Bacteria, Their Population Genetics, and Recombination. Cold Spring Harb. Perspect. Biol. 8, (2016).

71. Cvijović, I., Nguyen Ba, A. N. \& Desai, M. M. Experimental Studies of Evolutionary Dynamics in Microbes. Trends Genet. 34, 693-703 (2018).

72. Rocha, E. P. C. Neutral Theory, Microbial Practice: Challenges in Bacterial Population Genetics. Mol. Biol. Evol. 35, 1338-1347 (2018).

73. Wade, M. J. The co-evolutionary genetics of ecological communities. Nat. Rev. Genet. 8, 185-195 (2007).

74. Heath, K. D. \& Stinchcombe, J. R. Explaining mutualism variation: a new evolutionary paradox? Evolution 68, 309-317 (2014).

75. Elena, S. F. \& Lenski, R. E. Evolution experiments with microorganisms: the dynamics and genetic bases of adaptation. Nat. Rev. Genet. 4, 457-469 (2003).

76. Lapierre, P. \& Gogarten, J. P. Estimating the size of the bacterial pan-genome. Trends Genet. 25, 107-110 (2009).

77. Koonin, E. V. \& Wolf, Y. I. Evolution of microbes and viruses: a paradigm shift in evolutionary biology? Front. Cell. Infect. Microbiol. 2, 119 (2012).

78. Ferreiro, A., Crook, N., Gasparrini, A. J. \& Dantas, G. Multiscale Evolutionary Dynamics of Host-Associated Microbiomes. Cell 172, 1216-1227 (2018).

79. Kikuchi, Y., Hosokawa, T. \& Fukatsu, T. Specific developmental window for establishment of an insect-microbe gut symbiosis. Appl. Environ. Microbiol. 77, 4075-4081 (2011).

80. Kikuchi, Y. et al. Symbiont-mediated insecticide resistance. Proc. Natl. Acad. Sci. U. S. A. 109, 8618-8622 (2012).

81. Itoh, $\mathrm{H}$. et al. Infection dynamics of insecticide-degrading symbionts from soil to insects in response to insecticide spraying. ISME J. 12, 909-920 (2018).

82. Kohl, K. D., Weiss, R. B., Cox, J., Dale, C. \& Dearing, M. D. Gut microbes of mammalian herbivores facilitate intake of plant toxins. Ecol. Lett. 17, 1238-1246 (2014).

83. Miller, A. W., Kohl, K. D. \& Dearing, M. D. The gastrointestinal tract of the white-throated Woodrat (Neotoma albigula) harbors distinct consortia of oxalate-degrading bacteria. Appl. Environ. Microbiol. 80, 1595-1601 (2014).

84. Kohl, K. D. \& Dearing, M. D. The Woodrat Gut Microbiota as an Experimental System for Understanding Microbial Metabolism of Dietary Toxins. Front. Microbiol. 7, 1165 (2016).

85. Miller, A. W., Oakeson, K. F., Dale, C. \& Dearing, M. D. Effect of Dietary Oxalate on the Gut Microbiota of the Mammalian Herbivore Neotoma albigula. Appl. Environ. Microbiol. 82, 2669-2675 (2016).

86. Kohl, K. D., Stengel, A. \& Dearing, M. D. Inoculation of tannindegrading bacteria into novel hosts increases performance on tannin-rich diets. Environ. Microbiol. 18, 1720-1729 (2016).

87. Boone, C. K. et al. Bacteria associated with a tree-killing insect reduce concentrations of plant defense compounds. J. Chem. Ecol. 39, 1003-1006 (2013).

88. Berasategui, A. et al. Gut microbiota of the pine weevil degrades conifer diterpenes and increases insect fitness. Mol. Ecol. 26, 40994110 (2017).

89. Ceja-Navarro, J. A. et al. Gut microbiota mediate caffeine detoxification in the primary insect pest of coffee. Nat. Commun. 6, 7618 (2015).

90. Redman, R. S., Sheehan, K. B., Stout, R. G., Rodriguez, R. J. \& Henson, J. M. Thermotolerance generated by plant/fungal symbiosis. Science 298, 1581 (2002).

91. Rodriguez, R. J. et al. Stress tolerance in plants via habitat-adapted symbiosis. ISME J. 2, 404-416 (2008). 
bioRxiv preprint doi: https://doi.org/10.1101/700237; this version posted July 14,2019 . The copyright holder for this preprint (which was not certified by peer review) is the author/funder. All rights reserved. No reuse allowed without permission.

Henry al., 10072019 - preprint copy - BioRxiv

92. Webster, N. S. \& Reusch, T. B. H. Microbial contributions to the persistence of coral reefs. ISME J. 11, 2167-2174 (2017).

93. Bourne, D. G., Morrow, K. M. \& Webster, N. S. Insights into the Coral Microbiome: Underpinning the Health and Resilience of Reef Ecosystems. Annu. Rev. Microbiol. 70, 317-340 (2016).

94. Ainsworth, T. D., Thurber, R. V. \& Gates, R. D. The future of coral reefs: a microbial perspective. Trends Ecol. Evol. 25, 233-240 (2010).

95. Gilbert, S. F., Bosch, T. C. G. \& Ledón-Rettig, C. Eco-Evo-Devo: Developmental symbiosis and developmental plasticity as evolutionary agents. Nat. Rev. Genet. 16, 611 (2015).

96. Sachs, J. L., Skophammer, R. G. \& Regus, J. U. Evolutionary transitions in bacterial symbiosis. Proc. Natl. Acad. Sci. U. S. A. 108 Suppl 2, 10800-10807 (2011).

97. Bennett, G. M. \& Moran, N. A. Heritable symbiosis: The advantages and perils of an evolutionary rabbit hole. Proceedings of the National Academy of Sciences 112, 10169-10176 (2015).

98. Miller, E. T., Svanbäck, R. \& Bohannan, B. J. M. Microbiomes as Metacommunities: Understanding Host-Associated Microbes through Metacommunity Ecology. Trends Ecol. Evol. 33, 926-935 (2018).

99. West-Eberhard, M. Phenotypic Plasticity And The Origins Of Diversity. Annu. Rev. Ecol. Syst. 20, 249-278 (1989).

100. Bolnick, D. I. et al. Why intraspecific trait variation matters in community ecology. Trends Ecol. Evol. 26, 183-192 (2011).

101. Newell, P. D. \& Douglas, A. E. Interspecies interactions determine the impact of the gut microbiota on nutrient allocation in Drosophila melanogaster. Appl. Environ. Microbiol. 80, 788-796 (2014).

102. Keebaugh, E. S., Yamada, R., Obadia, B., Ludington, W. B. \& Ja, W. W. Microbial Quantity Impacts Drosophila Nutrition, Development, and Lifespan. iScience 4, 247-259 (2018).

103. Mushegian, A. A., Walser, J.-C., Sullam, K. E. \& Ebert, D. The microbiota of diapause: How host-microbe associations are formed after dormancy in an aquatic crustacean. J. Anim. Ecol. 87, 400-413 (2017).

104. Panke-Buisse, K., Poole, A. C., Goodrich, J. K., Ley, R. E. \& KaoKniffin, J. Selection on soil microbiomes reveals reproducible impacts on plant function. ISME J. 9, 980-989 (2015).

105. Rolig, A. S., Parthasarathy, R., Burns, A. R., Bohannan, B. J. M. \& Guillemin, K. Individual Members of the Microbiota Disproportionately Modulate Host Innate Immune Responses. Cell Host Microbe 18, 613-620 (2015).

106. Lau, J. A. \& Lennon, J. T. Rapid responses of soil microorganisms improve plant fitness in novel environments. Proc. Natl. Acad. Sci. U. S. A. 109, 14058-14062 (2012).

107. Newell, P. D. \& Douglas, A. E. Interspecies interactions determine the impact of the gut microbiota on nutrient allocation in Drosophila melanogaster. Appl. Environ. Microbiol. 80, 788-796 (2014).

108. Kikuchi, Y., Hosokawa, T. \& Fukatsu, T. Specific developmental window for establishment of an insect-microbe gut symbiosis. Appl. Environ. Microbiol. 77, 4075-4081 (2011).

109. Dickson, L. B. et al. Carryover effects of larval exposure to different environmental bacteria drive adult trait variation in a mosquito vector. Science Advances 3, e1700585 (2017).

110. Schwab, D. B., Riggs, H. E., Newton, I. L. G. \& Moczek, A. P. Developmental and Ecological Benefits of the Maternally Transmitted Microbiota in a Dung Beetle. Am. Nat. 188, 679-692 (2016).

111. Shin, S. C. et al. Drosophila microbiome modulates host developmental and metabolic homeostasis via insulin signaling. Science 334, 670-674 (2011).
112. Storelli, G. et al. Lactobacillus plantarum promotes Drosophila systemic growth by modulating hormonal signals through TORdependent nutrient sensing. Cell Metab. 14, 403-414 (2011).

113. Martino, M. E. et al. Bacterial Adaptation to the Host's Diet Is a Key Evolutionary Force Shaping Drosophila-Lactobacillus Symbiosis. Cell Host Microbe 24, 109-119.e6 (2018).

114. Panke-Buisse, K., Poole, A. C., Goodrich, J. K., Ley, R. E. \& KaoKniffin, J. Selection on soil microbiomes reveals reproducible impacts on plant function. ISME J. 9, 980-989 (2015).

115. Wagner, M. R. et al. Natural soil microbes alter flowering phenology and the intensity of selection on flowering time in a wild Arabidopsis relative. Ecol. Lett. 17, 717-726 (2014).

116. Lau, J. A. \& Lennon, J. T. Rapid responses of soil microorganisms improve plant fitness in novel environments. Proc. Natl. Acad. Sci. U. S. A. 109, 14058-14062 (2012).

117. Mushegian, A. A., Walser, J.-C., Sullam, K. E. \& Ebert, D. The microbiota of diapause: How host-microbe associations are formed after dormancy in an aquatic crustacean. J. Anim. Ecol. 87, 400-413 (2017).

118. Sison-Mangus, M. P., Mushegian, A. A. \& Ebert, D. Water fleas require microbiota for survival, growth and reproduction. ISME J. 9, 59-67 (2015).

119. Gilbert, S. F., Bosch, T. C. G. \& Ledón-Rettig, C. Eco-Evo-Devo: developmental symbiosis and developmental plasticity as evolutionary agents. Nat. Rev. Genet. 16, 611-622 (2015).

120. Vangay, P. et al. US Immigration Westernizes the Human Gut Microbiome. Cell 175, 962-972.e10 (2018).

121. Hillman, K. \& Goodrich-Blair, H. Are you my symbiont? Microbial polymorphic toxins and antimicrobial compounds as honest signals of beneficial symbiotic defensive traits. Curr. Opin. Microbiol. 31, 184-190 (2016).

122. Hoang, K. L., Morran, L. T. \& Gerardo, N. M. Experimental Evolution as an Underutilized Tool for Studying Beneficial Animal-Microbe Interactions. Front. Microbiol. 07, (2016).

123. Schlötterer, C., Kofler, R., Versace, E., Tobler, R. \& Franssen, S. U. Combining experimental evolution with next-generation sequencing: a powerful tool to study adaptation from standing genetic variation. Heredity 114, 431-440 (2015).

124. Burke, M. K. et al. Genome-wide analysis of a long-term evolution experiment with Drosophila. Nature 467, 587-590 (2010).

125. Orozco-terWengel, P. et al. Adaptation of Drosophila to a novel laboratory environment reveals temporally heterogeneous trajectories of selected alleles. Mol. Ecol. 21, 4931-4941 (2012).

126. Remolina, S. C., Chang, P. L., Leips, J., Nuzhdin, S. V. \& Hughes, K. A. Genomic basis of aging and life-history evolution in Drosophila melanogaster. Evolution 66, 3390-3403 (2012).

127. Jalvingh, K. M., Chang, P. L., Nuzhdin, S. V. \& Wertheim, B. Genomic changes under rapid evolution: selection for parasitoid resistance. Proceedings of the Royal Society B: Biological Sciences 281, 20132303-20132303 (2014).

128. Martins, N. E. et al. Host adaptation to viruses relies on few genes with different cross-resistance properties. Proceedings of the National Academy of Sciences 111, 5938-5943 (2014).

129. Jha, A. R. et al. Whole-Genome Resequencing of Experimental Populations Reveals Polygenic Basis of Egg-Size Variation in Drosophila melanogaster. Mol. Biol. Evol. 32, 2616-2632 (2015).

130. Kang, L., Aggarwal, D. D., Rashkovetsky, E., Korol, A. B. \& Michalak, P. Rapid genomic changes in Drosophila melanogaster adapting to desiccation stress in an experimental evolution system. BMC Genomics 17, (2016).

131. Michalak, P., Kang, L., Sarup, P. M., Schou, M. F. \& Loeschcke, V. Nucleotide diversity inflation as a genome-wide response to experimental lifespan extension in Drosophila melanogaster. $B M C$ Genomics 18, (2017). 
bioRxiv preprint doi: https://doi.org/10.1101/700237; this version posted July 14,2019 . The copyright holder for this preprint (which was not certified by peer review) is the author/funder. All rights reserved. No reuse allowed without permission.

Henry al., 10072019 - preprint copy - BioRxiv

132. Hardy, C. M. et al. Genome-Wide Analysis of Starvation-Selected Drosophila melanogaster: A Genetic Model of Obesity. Mol. Biol. Evol. 35, 50-65 (2018).

133. Broderick, N. A. \& Lemaitre, B. Gut-associated microbes of Drosophila melanogaster. Gut Microbes 3, 307-321 (2012).

134. Wagner, M. R. et al. Natural soil microbes alter flowering phenology and the intensity of selection on flowering time in a wild Arabidopsis relative. Ecol. Lett. 17, 717-726 (2014).

135. Bordenstein, S. R. \& Theis, K. R. Host Biology in Light of the Microbiome: Ten Principles of Holobionts and Hologenomes. PLOS Biol. 13, e1002226 (2015).

136. Mueller, U. G. \& Sachs, J. L. Engineering Microbiomes to Improve Plant and Animal Health. Trends Microbiol. 23, 606-617 (2015).

137. Alberdi, A., Aizpurua, O., Bohmann, K., Zepeda-Mendoza, M. L. \& Gilbert, M. T. P. Do Vertebrate Gut Metagenomes Confer Rapid Ecological Adaptation? Trends Ecol. Evol. 31, 689-699 (2016).

138. Carrier, T. J. \& Reitzel, A. M. The Hologenome Across Environments and the Implications of a Host-Associated Microbial Repertoire. Front. Microbiol. 8, 802 (2017).

139. Hendry, A. P. Eco-evolutionary Dynamics. (Princeton University Press, 2017).

140. Hurst, G. D. D. Extended genomes: symbiosis and evolution. Interface Focus 7, 20170001 (2017).

141. Bang, C. et al. Metaorganisms in extreme environments: do microbes play a role in organismal adaptation? Zoology $127,1-19$ (2018).

142. Hoyt, J. R. et al. Bacteria isolated from bats inhibit the growth of Pseudogymnoascus destructans, the causative agent of white-nose syndrome. PLoS One 10, e0121329 (2015).

143. Cheng, T. L. et al. Efficacy of a probiotic bacterium to treat bats affected by the disease white-nose syndrome. J. Appl. Ecol. 54, 701-708 (2016).

144. Woodhams, D. C., Bletz, M., Kueneman, J. \& McKenzie, V. Managing Amphibian Disease with Skin Microbiota. Trends Microbiol. 24, 161-164 (2016).

145. Weiss, B. \& Aksoy, S. Microbiome influences on insect host vector competence. Trends Parasitol. 27, 514-522 (2011).

146. Zitvogel, L., Ma, Y., Raoult, D., Kroemer, G. \& Gajewski, T. F. The microbiome in cancer immunotherapy: Diagnostic tools and therapeutic strategies. Science 359, 1366-1370 (2018).

147. Toju, H. et al. Core microbiomes for sustainable agroecosystems. Nature Plants 4, 247-257 (2018).

148. Hammer, T. J., Janzen, D. H., Hallwachs, W., Jaffe, S. P. \& Fierer, $\mathrm{N}$. Caterpillars lack a resident gut microbiome. Proceedings of the National Academy of Sciences 114, 9641-9646 (2017).

149. Herrera Paredes, S. et al. Design of synthetic bacterial communities for predictable plant phenotypes. PLoS Biol. 16, e2003962 (2018).

150. Agler, M. T. et al. Microbial Hub Taxa Link Host and Abiotic Factors to Plant Microbiome Variation. PLoS Biol. 14, e1002352 (2016).

151. Chaston, J. M., Newell, P. D. \& Douglas, A. E. Metagenome-wide association of microbial determinants of host phenotype in Drosophila melanogaster. MBio 5, e01631-14 (2014).

152. Gould, A. L. et al. High-dimensional microbiome interactions shape host fitness. (2017). doi:10.1101/232959

153. Garud, N. R., Good, B. H., Hallatschek, O. \& Pollard, K. S. Evolutionary dynamics of bacteria in the gut microbiome within and across hosts. (2017). doi:10.1101/210955

154. Truong, D. T., Tett, A., Pasolli, E., Huttenhower, C. \& Segata, N. Microbial strain-level population structure and genetic diversity from metagenomes. Genome Res. 27, 626-638 (2017).
155. Spor, A., Koren, O. \& Ley, R. Unravelling the effects of the environment and host genotype on the gut microbiome. Nat. Rev. Microbiol. 9, 279-290 (2011).

156. Wade, M. J. The co-evolutionary genetics of ecological communities. Nat. Rev. Genet. 8, 185-195 (2007).

157. Hird, S. M. Evolutionary Biology Needs Wild Microbiomes. Front. Microbiol. 8, 725 (2017).

158. Kohl, K. D. An Introductory 'How-to' Guide for Incorporating Microbiome Research into Integrative and Comparative Biology. Integr. Comp. Biol. 57, 674-681 (2017).

159. Marchesi, J. R. \& Ravel, J. The vocabulary of microbiome research: a proposal. Microbiome 3, 31 (2015). 
Henry al., 10072019 - preprint copy - BioRxiv

\section{SUPPLEMENTAL METHODS FOR QUANTITATIVE GENETIC SIMULATIONS:}

In order to simulate the effect of the microbiome on selection response, we considered families with three offspring each. This scenario is described by a block diagonal kinship matrix

$$
K=\left(\begin{array}{cccc}
k_{1} & 0 & \cdots & 0 \\
0 & k_{2} & \cdots & 0 \\
\vdots & \vdots & \ddots & \vdots \\
0 & 0 & \cdots & k_{n}
\end{array}\right) \text {, where each block } \quad k_{i}=\left(\begin{array}{ccccc}
1 & 0 & 0.5 & 0.5 & 0.5 \\
0 & 1 & 0.5 & 0.5 & 0.5 \\
0.5 & 0.5 & 1 & 0.5 & 0.5 \\
0.5 & 0.5 & 0.5 & 1 & 0.5 \\
0.5 & 0.5 & 0.5 & 0.5 & 1
\end{array}\right) \text { corresponds to one family. }
$$

The contribution of the host genome to the phenotype is given by $g_{h o s t} \sim \operatorname{MVN}\left(0, h_{h o s t}^{2} * K\right)$, in accordance with quantitative genetics theory ${ }^{11}$. Extending the conventional theoretical framework, we define the phenotypic contribution of the microbiome as

$g_{\text {micro }} \sim \operatorname{MVN}\left(0, h_{\text {micro }}^{2} * E \circ K\right)$, where $h_{\text {micro is the phenotypic variance explained by the microbiome in the parental }}^{2}$ 
Henry al., 10072019 - preprint copy - BioRxiv

\[ E=\left(\begin{array}{cccc}e_{1} & 0 & \cdots & 0 \\ 0 & e_{2} & \cdots & 0 \\ \vdots & \vdots & \ddots & \vdots \\ 0 & 0 & \cdots & e_{n}\end{array}\right) \text { is a block diagonal matrix determining the transmission noise, where each block } \]
generation.

$e_{i}=\left(\begin{array}{ccccc}1 & 1 / e_{i, t} & 1 / e_{i, t} & 1 / e_{i, t} & 1 / e_{i, t} \\ 1 / e_{i, t} & 1 & 1 / e_{i, t} & 1 / e_{i, t} & 1 / e_{i, t} \\ 1 / e_{i, t} & 1 / e_{i, t} & 1 & 1 / e_{i, t} & 1 / e_{i, t} \\ 1 / e_{i, t} & 1 / e_{i, t} & 1 / e_{i, t} & 1 & 1 / e_{i, t} \\ 1 / e_{i, t} & 1 / e_{i, t} & 1 / e_{i, t} & 1 / e_{i, t} & 1\end{array}\right)$ corresponds to one family.

The Hadamard product ${ }^{22} E \circ K$ thus produces a matrix where the co-variances are down weighted by a factor $e_{i, t}$ per family. For simplicity, the transmission noise $e_{i, t}$ is sampled from a chi-square distribution, the degrees of freedom determining the amount of noise $\left(\mathrm{df}=1,3\right.$, and 5). Finally, the phenotype is defined as $y=g_{\text {host }}+g_{\text {micro }}+e$, where $e \sim N\left(0,1-h_{\text {host }}^{2}-h_{\text {micro }}^{2}\right)$, thus keeping total VP is kept constant. 


\section{SUPPLEMENTAL METHODS FOR E\&R ANALYSES:}

We downloaded SRA files for the 10 Evolve and Resequence (E\&R) experiments from NCBI. The E\&R approach sequences pools of individuals from different selection regimes, but each E\&R study had different levels of replication, summarized in Supp. Table 1. Our analyses captured a wide range of different selection pressures, from life-history traits to abiotic pressures to pathogen pressures. Raw sequences were cleaned using Trimmomatic ${ }^{3}$ to remove sequencing adapters, remove low quality reads (average quality per base $>15$ ), and drop reads shorter than 20 bases long. Then, bacterial reads were called using Kraken ${ }^{4}$ to family level. Relative abundance of bacterial families were determined using Bracken ${ }^{5}$. Because the E\&R sequencing was not performed explicitly for the microbiome, we needed to remove potential contaminants. We removed any low abundance bacterial family that was assigned fewer than 100 reads. Microbial diversity was calculated using the Shannon diversity index.

To test if microbial diversity was different between control and evolved lines, we compared Shannon diversity. We determined significance using a t-test (see Supp. Table 2 for significance summary). We then tested if two factors explained differences in microbial diversity between control and selected lines: length of selection and Wolbachia.

First, length of selection ranged from 5-605 generations. We reasoned that selection response in the microbiome might be influenced by length of selection; the longer the selection, the more divergent the microbiome between control and evolved lines. To test if length of selection was correlated with changes in microbial diversity, we calculated the average microbial diversity for the control lines. We then subtracted the diversity of each evolved line from the averaged control diversity to calculate change in diversity. Because we had positive and negative changes in diversity, we used the absolute difference. We performed a linear regression between change in diversity and the log10 length of selection in $\mathrm{R}$.

Second, we tested the effects of Wolbachia on changes in the selection response of the microbiome. As mentioned in the full text, Wolbachia is a facultative, intracellular bacteria transmitted exclusively from mother to offspring. Wolbachia has no known environmental reservoir and cannot exist outside of the host. For the extended genotype, these intracellular, maternally transmitted bacteria have the same evolutionary trajectory as the host genome; the shared transmission mode limits their ability to rapidly respond to stressful environments. So, we tested if Wolbachia influenced the response to selection in the microbiome. To test the role of Wolbachia, we removed Wolbachia reads from the communities then recalculated Shannon diversity. We compared if bacterial communities without Wolbachia significantly differed between control and evolved lines using a t-test. 
bioRxiv preprint doi: https://doi.org/10.1101/700237; this version posted July 14,2019 . The copyright holder for this preprint (which was not certified by peer review) is the author/funder. All rights reserved. No reuse allowed without permission.

Henry al., 10072019 - preprint copy - BioRxiv

\section{References from supplement:}

1. Lynch, M. \& Walsh, B. Genetics and Analysis of Quantitative Traits. (Sinauer Associates Incorporated, 1998).

2. Styan, G. P. H. Hadamard products and multivariate statistical analysis. Linear Algebra and its Applications 6, 217-240 (1973).

3. Bolger, A. M., Lohse, M. \& Usadel, B. Trimmomatic: a flexible trimmer for Illumina sequence data. Bioinformatics 30, 2114-2120 (2014).

4. Wood, D. E. \& Salzberg, S. L. Kraken: ultrafast metagenomic sequence classification using exact alignments. Genome Biol. 15, R46 (2014).

5. Lu, J., Breitwieser, F. P., Thielen, P. \& Salzberg, S. L. Bracken: Estimating species abundance in metagenomics data. (2016). doi:10.1101/051813 
bioRxiv preprint doi: https://doi.org/10.1101/700237; this version posted July 14, 2019. The copyright holder for this preprint (which was not certified by peer review) is the author/funder. All rights reserved. No reuse allowed without permission.

Henry al., 10072019 - preprint copy - BioRxiv

Supp. Table 1: Evolve \& Resequence data

\begin{tabular}{|c|c|c|c|c|}
\hline Pressure & Evolved Phenotype & $\begin{array}{l}\text { Length } \\
\text { Selection } \\
\text { (generations) }\end{array}$ & Wolbachia & Sequencing \\
\hline $\begin{array}{l}\text { Accelerated } \\
\text { development }^{1}\end{array}$ & $\begin{array}{l}\text { Flies developed from } \\
\text { egg to adult } 20 \% \text { faster } \\
\text { than control lines }\end{array}$ & 605 & Infected & $\begin{array}{l}25 \text { females pooled from each line; } 4 \\
\text { control and } 4 \text { evolved }\end{array}$ \\
\hline $\begin{array}{l}\text { Delayed } \\
\text { reproduction }\end{array}$ & $\begin{array}{l}\text { Age of reproduction } \\
\text { increased from } 28 \text { to } 40 \\
\text { days }\end{array}$ & 50 & Uninfected & $\begin{array}{l}100 \text { females pooled from each line; } 3 \\
\text { control and } 3 \text { evolved }\end{array}$ \\
\hline Increased lifespan ${ }^{3}$ & $\begin{array}{l}\text { Median lifespan was } \\
\text { increased from } 4 \text { weeks } \\
\text { to } 7-8 \text { weeks }\end{array}$ & 48 & Uninfected & $\begin{array}{l}250 \text { males }+250 \text { females pooled } \\
\text { from each line; } 3 \text { control and } 3 \\
\text { evolved }\end{array}$ \\
\hline Egg size $^{4}$ & $\begin{array}{l}\text { Egg size was selected } \\
\sim 20 \% \text { larger and } \\
\text { smaller eggs }\end{array}$ & 16 & Infected & $\begin{array}{l}100 \text { females pooled from each line; } 3 \\
\text { control, } 3 \text { small, } 3 \text { large }\end{array}$ \\
\hline $\begin{array}{l}\text { Desiccation } \\
\text { resistance }^{5}\end{array}$ & $\begin{array}{l}\text { Desiccation resistance } \\
\text { (hrs until } 80 \% \\
\text { mortality) increased } 70- \\
80 \%\end{array}$ & 48 & Infected & $\begin{array}{l}100 \text { females pooled from each line; } 3 \\
\text { control and } 3 \text { evolved }\end{array}$ \\
\hline $\begin{array}{l}\text { Fluctuating } \\
\text { temperatures }\end{array}$ & $\begin{array}{l}\text { Survival under } \\
\text { fluctuating temps } 18- \\
28^{\circ} \mathrm{C} \text { daily }\end{array}$ & 37 & Infected & $\begin{array}{l}500 \text { females pooled for each line at } \\
\text { different time points; beginning, } \\
\text { middle, and end; } 3 \text { control and } 3 \\
\text { evolved--only compared beginning } \\
\text { and end }\end{array}$ \\
\hline $\begin{array}{l}\text { Salt }+ \text { cadmium } \\
\text { resistance }{ }^{7}\end{array}$ & $\begin{array}{l}\text { Survival in constant, } \\
\text { spatially, temporally } \\
\text { varying salt and/or } \\
\text { cadmium }\end{array}$ & 42 & Infected & $\begin{array}{l}70 \text { females pooled from each line; } 3 \\
\text { control lines and } 5 \text { lines for each } \\
\text { selection pressure }\end{array}$ \\
\hline $\begin{array}{l}\text { Starvation } \\
\text { resistance }^{8}\end{array}$ & $\begin{array}{l}\text { Starvation resistance } \\
\text { (hrs to death w/o food) } \\
\text { increased } \sim 25 \%\end{array}$ & 83 & Infected & $\begin{array}{l}100 \text { females pooled for each line; } 3 \\
\text { control and } 3 \text { evolved lines }\end{array}$ \\
\hline $\begin{array}{l}\text { Parasitoid } \\
\text { resistance }^{9}\end{array}$ & $\begin{array}{l}\text { Resistance to parasitoid } \\
\text { increased from } 20 \% \text { to } \\
50 \%\end{array}$ & 5 & Uninfected & $\begin{array}{l}50 \text { females pooled from each line; } 16 \\
\text { control and } 16 \text { evolved lines }\end{array}$ \\
\hline Viral resistance ${ }^{10}$ & $\begin{array}{l}\text { Resistance } r \text { to } \\
\text { Drosophila C virus } \\
\text { increased from } 25 \% \text { to } \\
75 \%\end{array}$ & 20 & Infected & $\begin{array}{l}200 \text { individuals pooled from each } \\
\text { line; } 4 \text { control, } 4 \text { procedure control, } \\
4 \text { evolved }\end{array}$ \\
\hline
\end{tabular}


bioRxiv preprint doi: https://doi.org/10.1101/700237; this version posted July 14,2019 . The copyright holder for this preprint (which was not certified by peer review) is the author/funder. All rights reserved. No reuse allowed without permission.

Henry al., 10072019 - preprint copy - BioRxiv

\section{Evolve and Resequence experiments:}

1. Burke MK, Dunham JP, Shahrestani P, Thornton KR, Rose MR, Long AD. 2010. Genome-wide analysis of a long-term evolution experiment with Drosophila. Nature 467:587.

2. Remolina SC, Chang PL, Leips J, Nuzhdin SV, Hughes KA. 2012. Genomic basis of aging and life-history evolution in Drosophila melanogaster. Evolution 66:3390-3403.

3. Michalak P, Kang L, Sarup PM, Schou MF, Loeschcke V. 2017. Nucleotide diversity inflation as a genome-wide response to experimental lifespan extension in Drosophila melanogaster. BMC Genomics 18:84.

4. Jha AR, Miles CM, Lippert NR, Brown CD, White KP, Kreitman M. 2015. Whole-genome resequencing of experimental populations reveals polygenic basis of egg-size variation in Drosophila melanogaster. Molecular Biology and Evolution 32:2616-2632.

5. Kang L, Aggarwal DD, Rashkovetsky E, Korol AB, Michalak P. 2016. Rapid genomic changes in Drosophila melanogaster adapting to desiccation stress in an experimental evolution system. BMC Genomics 17:233.

6. Orozco-terWengel P, Kapun M, Nolte V, Kofler R, Flatt T, Schlötterer C. 2012. Adaptation of Drosophila to a novel laboratory environment reveals temporally heterogeneous trajectories of selected alleles. Molecular Ecology 21:4931-4941. 7. Huang Y, Wright SI, Agrawal AF. 2014. Genome-wide patterns of genetic variation within and among alternative selective regimes. PLoS Genetics 10:e1004527.

8. Hardy CM, Burke MK, Everett LJ, Han MV, Lantz KM, Gibbs AG. 2017. Genome-wide analysis of starvationselected Drosophila melanogaster - a genetic model of obesity. Molecular biology and evolution 35:50-65.

9. Jalvingh KM, Chang PL, Nuzhdin SV, Wertheim B. 2014. Genomic changes under rapid evolution: selection for parasitoid resistance. Proceedings of the Royal Society of London B: Biological Sciences 281:20132303.

10. Martins NE, Faria VG, Nolte V, Schlötterer C, Teixeira L, Sucena É, Magalhães S. 2014. Host adaptation to viruses relies on few genes with different cross-resistance properties. Proceedings of the National Academy of Sciences 111:5938-5943. 
Supp. Table 2: Statistical differences between control and evolved microbiomes

\begin{tabular}{|c|c|c|c|}
\hline Pressure & test stat & $\mathrm{df}$ & significance \\
\hline accelerated development & $\mathrm{t}=-8.134$ & $\mathrm{df}=3.006$ & $\mathrm{p}$-value $=0.004$ \\
\hline accelerated development without Wolbachia & $\mathrm{t}=-5.548$ & $\mathrm{df}=3.060$ & $\mathrm{p}$-value $=0.011$ \\
\hline delayed reproduction & $\mathrm{t}=3.567$ & $\mathrm{df}=33.666$ & $\mathrm{p}$-value $=0.001$ \\
\hline increased lifespan & $\mathrm{t}=1.369$ & $\mathrm{df}=3.183$ & $\mathrm{p}$-value $=0.260$ \\
\hline egg size & $\mathrm{t}=0.213$ & $\mathrm{df}=3.104$ & $\mathrm{p}$-value $=0.844$ \\
\hline egg size without Wolbachia & $\mathrm{t}=0.251$ & $\mathrm{df}=3.075$ & $\mathrm{p}$-value $=0.817$ \\
\hline desiccation resistance & $\mathrm{t}=2.881$ & $\mathrm{df}=2.225$ & $\mathrm{p}$-value $=0.090$ \\
\hline desiccation resistance without Wolbachia & $\mathrm{t}=0.394$ & $\mathrm{df}=3.985$ & $\mathrm{p}$-value $=0.714$ \\
\hline fluctuating temperature & $\mathrm{t}=1.234$ & $\mathrm{df}=7.996$ & $\mathrm{p}$-value $=0.252$ \\
\hline fluctuating temperature without Wolbachia & $\mathrm{t}=-4.122$ & $\mathrm{df}=6.880$ & $\mathrm{p}$-value $=0.005$ \\
\hline salt and cadmium resistance & $\mathrm{t}=1.4294$ & $\mathrm{df}=2.285$ & $\mathrm{p}$-value $=0.274$ \\
\hline salt and cadmium resistance without Wolbachia & $\mathrm{t}=1.4294$ & $\mathrm{df}=2.285$ & $\mathrm{p}$-value $=0.2743$ \\
\hline starvation resistance & $\mathrm{t}=9.024$ & $\mathrm{df}=2.460$ & $\mathrm{p}$-value $=0.006$ \\
\hline starvation resistance without Wolbachia & $t=-0.973$ & $\mathrm{df}=2.161$ & $\mathrm{p}$-value $=0.426$ \\
\hline parasitoid resistance & $\mathrm{t}=2.186$ & $\mathrm{df}=28.389$ & $\mathrm{p}$-value $=0.037$ \\
\hline viral resistance & $\mathrm{t}=4.262$ & $\mathrm{df}=9.819$ & $\mathrm{p}$-value $=0.002$ \\
\hline viral resistance without Wolbachia & $\mathrm{t}=-2.851$ & $\mathrm{df}=7.187$ & $\mathrm{p}$-value $=0.024$ \\
\hline
\end{tabular}


bioRxiv preprint doi: https://doi.org/10.1101/700237; this version posted July 14,2019 . The copyright holder for this preprint (which was not certified by peer review) is the author/funder. All rights reserved. No reuse allowed without permission.

Henry al., 10072019 - preprint copy - BioRxiv

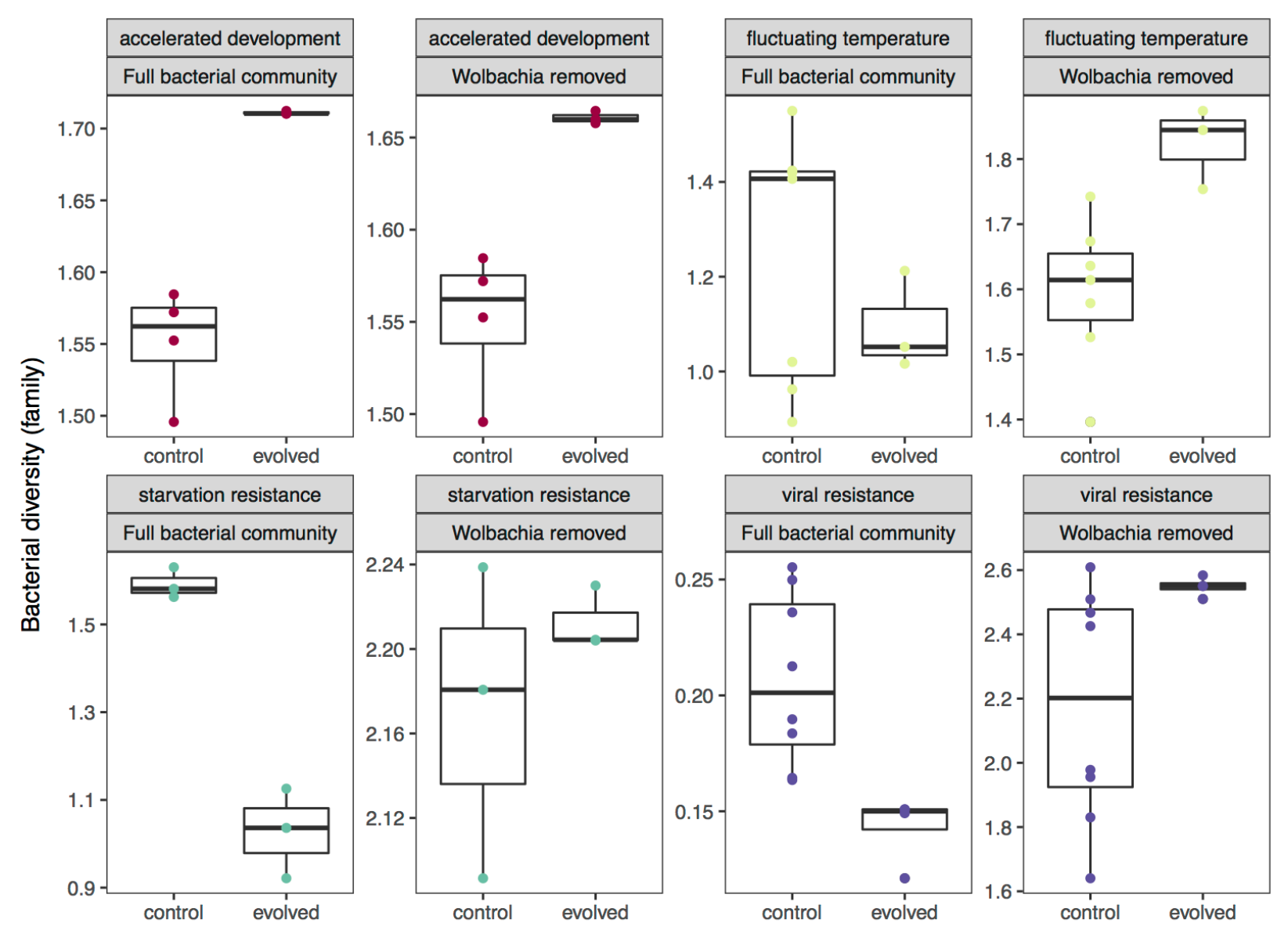

Supp Fig. 1: Removing Wolbachia frequently changes the response of the evolved microbiome (Supp. Table 2 for statistical summary). First, in accelerated development, removing Wolbachia did not affect bacterial diversity between control and evolved lines. Second, removing Wolbachia lead to increase in environmentally acquired bacterial diversity in the evolved lines under fluctuating temperatures. Third, removing Wolbachia shows that environmentally acquired bacteria did not respond to selection in starvation resistance as there was no different between control and evolved lines. Finally, in viral resistance, including Wolbachia showed a reduced microbial diversity in evolved lines. However, removing Wolbachia increased environmentally acquired bacterial diversity in evolved lines. 